As in Greenland, the high accumulation rate and great ice thickness will permit high-confidence borehole thermometry-based temperature estimates for the past glacial period. Other Antarctic borehole thermometry efforts have been stymied by the low accumulation rate. WAIS Divide should provide the first reliable direct temperature estimate of the last glacial maximum in Antarctica. Other borehole logging (optical, sonic) will place unique constraints on ice deformation, which combined with accurate surface temperature history, timescale, and accumulation rate, will make a potent synergy for glaciological modeling of the history of the WAIS. This effort will address questions about the stability of this marine-based ice sheet, which would raise sea level $5 \mathrm{~m}$ if melted.

\section{Wider perspectives of the WAIS project}

International collaboration figures prominently in the WAIS Divide ef- fort. WAIS Divide is under the umbrella of the recently established International Partnerships for Ice Coring Science (IPICS), although its planning long predates IPICS. WAIS Divide is one of the first elements to get underway in the IPICS 40,000 Year Network, which will map spatial variation at the regional scale in order to better understand the dynamics of the last deglaciation (see Brook, this issue). The importance of spatial differences between cores within Antarctica has been highlighted recently by the Siple Dome record (Taylor et al., 2004). Improved understanding of regional variations in climate during the past $100 \mathrm{kyr}$ will help separate global from regional signals.

International collaboration has already greatly aided the DISC deep drill development, and it is anticipated that international partnerships on WAIS Divide drilling and science will continue at a heightened pace in the context of the International Polar
Year (2007-2008). Bottom-up, individual investigator-driven international collaborations on WAIS Divide are highly encouraged, although no formal, top-down structure for collaboration has been imposed.

\section{REFERENCES}

Brook, E.J., White, J.W.C., Schilla, A.S.M., Bender, M.L., Barnett, B., Severinghaus, J.P., Taylor, K.C., Alley, R.B., Steig, E.J., 2005: Timing of millennialscale climate change at Siple Dome, West Antarctica, during the last glacial period, Quaternary Science Reviews, 24: 1333-1343.

Taylor, K.C., White, J.W.C. Severinghaus, J.P., Brook, E.J., Mayewski, P.A., Alley, R.B., Steig, E.J., Spencer, M.K., Meyerson, E., Meese, D.A., Lamorey, G.W., Grachev, A., Gow, A.J. and Barnett, B.A., 2004: Abrupt climate change around $22 \mathrm{ka}$ on the Siple Coast of Antarctica, Quat. Sci. Rev., 23: 7-15. Severinghaus, J.P., Grachev, A., Luz, B., and Caillon, N., A, 2003: method for precise measurement of argon 40/36 and krypton/argon ratios in trapped air in polar ice with applications to past firn thickness and abrupt climate change in Greenland and at Siple Dome, Antarctica, Geochim. Cosmochim. Acta, 67: 325-343.

\title{
International Trans Antarctic Scientific Expedition (ITASE)
}

\section{Paul Andrew Mayewski}

Climate Change Institute, University of Maine, Orono, USA; paul.mayewski@maine.edu

\section{Introduction}

ITASE has as its primary aim the collection and interpretation of a continent-wide array of environmental parameters (Fig. 1), assembled through the coordinated efforts of scientists from 20 nations. ITASE offers the groundbased opportunities of traditional style traverse travel, coupled with the modern technology of GPS, crevasse detecting radar, satellite communications and multi-disciplinary research (Fig. 2). By operating predominantly in the mode of an oversnow traverse, ITASE offers scientists the opportunity to experience the dynamic range of the Antarctic environment. The combination of disciplines represented by ITASE provides a unique, multi-dimensional ( $x, y$, $z$ and time) view of the ice sheet and its history. As of 2004, ITASE has completed $>20,000 \mathrm{~km}$ of snow radar, recovered more than $240 \mathrm{firn} / \mathrm{ice}$ cores (total depth

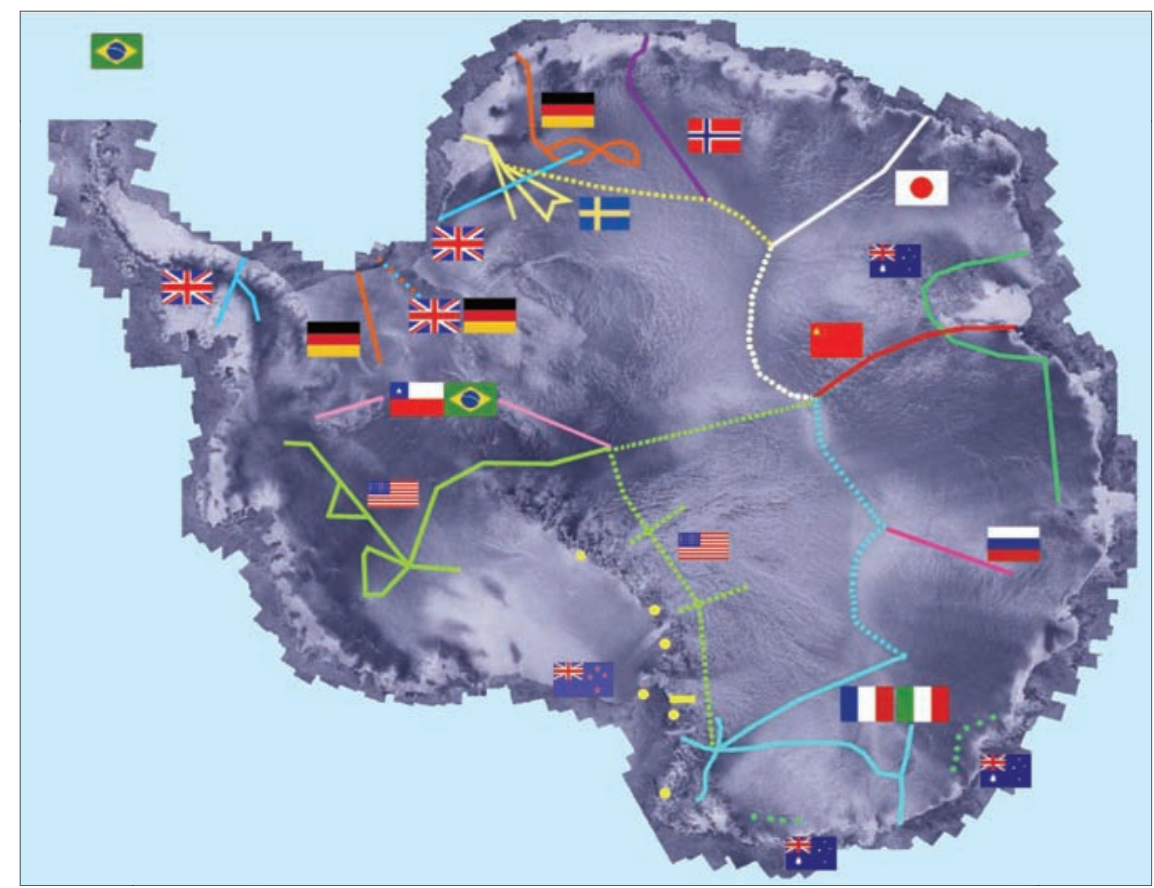

Fig. 1: ITASE national traverse routes superimposed on RADARSAT image. Solid lines represent completed traverses, dashed represent proposed or planned traverses.

$7000 \mathrm{~m})$, remotely penetrated to $\sim 4000 \mathrm{~m}$ into the ice sheet, and sampled the atmosphere to heights of $>20 \mathrm{~km}$.

\section{Results}

Although full-scale reconstructions of past climate over Antarctica have yet to be finalized, 


\section{Science Highlights: Ice Core Science}

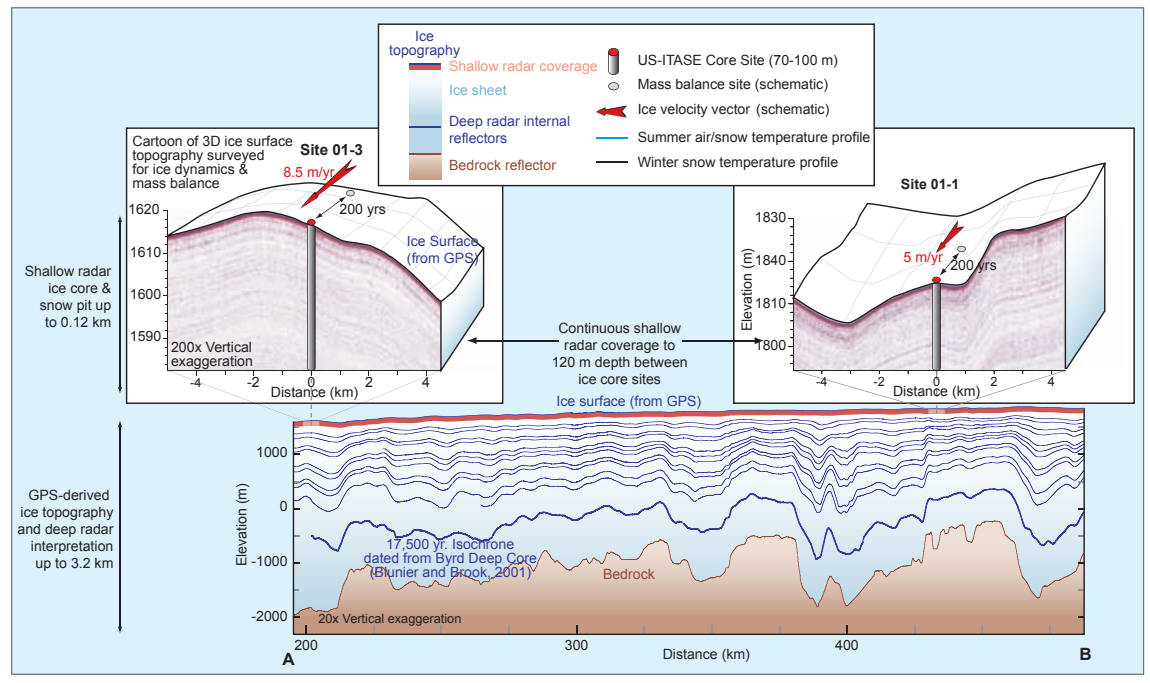

Fig. 2: Multi-dimensional approach to the multi-disciplinary ITASE objectives. Studies at a variety of spatial scales extending from the subglacial bedrock to the surface. Ice core sites along each traverse route produce 200-1000+ year annually dated climate records. Ice core site selection is determined by field interpretation of shallow radar data. Numerous measurements are made at each core site to provide context for the ice core climate records. These measurements include: high-resolution surface topography maps; snow pit measurements of density, chemistry, stable isotopes, temperature; and meteorological data. Ice mass balance and horizontal velocity studies located 200 years upstream provide past ice flow history for the ice cores. Shallow and deep-penetrating radio echo sounding data tie the ice cores together and provide large-scale context for ITASE cores and future deep ice core climate records. Internal stratigraphy in both radio echo sounding records represents isochronal events, and a record of depositional and ice flow history along the traverse. The radar data and interpretation, and ice topography along the radar profiles shown here are actual examples of the 2001 US-ITASE season. Figure by Brian Welch, St. Olaf College, US ITASE.

ITASE has pioneered calibration tools, reconstruction of climate indices, and evidence for climate forcing, using single-sites through to multiple arrays of sites. Initial syntheses of combined ITASE and deep ice core records demonstrate that inclusion of instrumentally calibrated ITASE ice core records allows the previously unavailable reconstruction of past regional to continental scale variability in atmospheric circulation and temperature. Emerging results demonstrate the utilization of ITASE records in comparisons with meteorological reanalysis products. Connections are now noted between ITASE climate proxies and global scale climate indices such as ENSO, in addition to major atmospheric circulation features over the Southern Hemisphere, such as the Amundsen Sea Low, East Antarctic High, and Antarctic Oscillation. Large-scale calibrations between satellite-deduced surface temperature and ITASE ice core proxies for temperature are also now available. ITASE is also developing proxies for sea ice, a critical component in the climate system. ITASE research is also fo- cused on understanding the factors that control climate variability over Antarctica and the Southern Ocean.

Understanding the distribution of snow precipitation over the Antarctic continent, and the surface processes on different spatial and temporal scales that redistribute this precipitation, is the area of greatest common interest between ITASE and another SCAR (Scientific Committee on Antarctic Research) activity, Ice Sheet Mass Balance and Sea Level (ISMASS). ITASE research reveals high variability in surface mass balance and the fact that single cores, stakes, and snowpits do not represent the geographical and environmental characteristics of a local region. Field observations show that the interaction of surface wind and subtle variations of surface slope have a considerable impact on the spatial distribution of snow at short and long spatial scales. Data collected in the ITASE framework and by associated projects (EPICA DC and DML, Siple Dome, Law Dome, Dome Fuji) also reveals systematic biases compared to previous compilations.

\section{Outlook}

Field measurements including new techniques, e.g. Lidar and airborne coherent GPR, laboratory ice flow studies, new computer modeling techniques, including new remote sensing techniques, e.g. Satellite Radar (SAR) interferometry, all contribute to ISMASS and ITASE goals. The extensive use along ITASE traverses of new techniques like GPR and GPS, integrated with core data, provide detailed information on surface mass balance. Some GPR layers have been surveyed extensively throughout Antarctica and they can be used as historical benchmarks to study past accumulation rates. In addition, coupling ground survey data with satellitebased observations provides new tools for measuring, for example, ice surface velocity and ice sheet surface temperature.

The growing ITASE database has the potential to explore temporal variability and recent evolution of Antarctic climate, utilizing an unprecedented spatio-temporal array. Data extraction and validation activities are an essential preliminary to the synthesis task. Such activities, together with the development of instrumental calibration techniques, have been a significant component of ITASE studies. Maps of surface distribution of chemical species (Bertler et al., in press) indicate the unprecedented scope for exploring climate variability as

\section{Project facts}

\section{Project: ITASE}

Contact: Paul Mayewski, paul.mayewski@maine.edu

Participants: Scientific and logistics institutions from 20 nations: Argentina, Australia, Belgium, Brazil, Canada, Chile, China, France, Germany, India, Italy, Japan, The Netherlands, New Zealand, Norway, Russia, South Korea, Sweden, UK, USA.

Funding: National contributions

Where: Antarctica

When: Endorsed by the Scientific Committee on Antarctic Research (SCAR). Activities since 1992 and ongoing.

What: Snow pits, shallow and intermediate ice cores covering decades to millennia, multiparameter analysis

Web page: www.ume.maine.edu/itase/ 
extended time-series become available over broad regions through ITASE and deep drilling projects. The Antarctic-wide comparison of glaciochemical records provides a unique opportunity to achieve an understanding of the fundamental factors that ultimately control the chemistry of a snow or ice sample. The ability to determine individual sources and pathways of aerosols, as well as mechanisms that rule precipitation efficiency and postdepositional effects, will allow the exceptionally detailed and accurate interpretation of glaciochemical records necessary for reconstructing past climate conditions with nearinstrumental quality.

\section{Note:}

This article was abstracted from Mayewski et al., in press. This paper summarizes ITASE accomplishments with references. For details concerning national programs, the ITASE Science and Implementation Plan (Mayewski and Goodwin, 1997), and other ITASE information refer to the SCAR Project Office maintained at the Climate Change Institute, University of Maine (www.ume. maine.edu/itase/).

\section{REFERENCES}

Bertler, N., Mayewski, P.A., Aristarain, A. and 46 others, in press: Snow chemistry across Antarctica, Annals of Glaciology.
Mayewski, P.A. and Goodwin, I. 1997: ITASE Science and Implementation Plan, Joint PAGES/GLOCANT Report. PAGES IPO, Bern - Switzerland

Mayewski, P.A., Frezzotti, M., Bertler, N., van Ommen, T., Hamilton, G.H., Jacka, J., Welch, B., Frey, M., Dahe, Q., Ren, J., Simoes, J., Fily, M., Oerter, H. Nishio, F., lasaksson, E., Mulvaney, R., Holmund, P., Lipenkov, V. and Goodwin, I., in press: The International Trans-Antarctic Scientific Expedition (ITASE) - An Overview, Annals of Glaciology.

\section{A new 3000 m deep ice core drilled at Dome Fuji, Antarctica}

YoshiYuki FUJII

National Institute of Polar Research, Tokyo, Japan; fujii@nipr.ac.jp

\section{Introduction}

On 23 January 2006, the Japanese Antarctic Research Expedition (JARE) succeeded in drilling a 3029 $m$ deep ice core at Dome Fuji in East Antarctica $\left(77^{\circ} 19^{\prime} 01^{\prime \prime} \mathrm{S}, 39^{\circ} 42^{\prime} 12^{\prime \prime} \mathrm{E}\right.$, $3810 \mathrm{~m}$ asl; Fig. 1). Dome Fuji is the third place where a more than 3000 $\mathrm{m}$ deep ice core was collected in Antarctica, after Vostok (3623 m in depth, January 1998) and Dome C (3270 $\mathrm{m}$ in depth, December 2004). The drilling will be continued next season in order to hit bedrock, which is estimated to be located $3030 \pm 15 \mathrm{~m}$ below the surface.

A previous deep ice core, of 2503 m length, was drilled at Dome Fuji in December 1996, tracing back to past $340 \mathrm{ka}$. The high resolution stable isotope record $\left(\delta^{18} \mathrm{O}\right)$ showed an extraordinary coherence (Watanabe et al., 2003) with the deep ice core from Vostok (Petit et al., 1999), which also reaches as far back in time but is located $1500 \mathrm{~km}$ away from Dome Fuji. This fact strongly supports a homogeneous climate development over the last 340,000 years on the high plateau of East Antarctica.

\section{Drilling of the new ice core}

During the 1996 drilling, the drill got stuck in the borehole and was not able to be recovered. A new drilling site was constructed in the

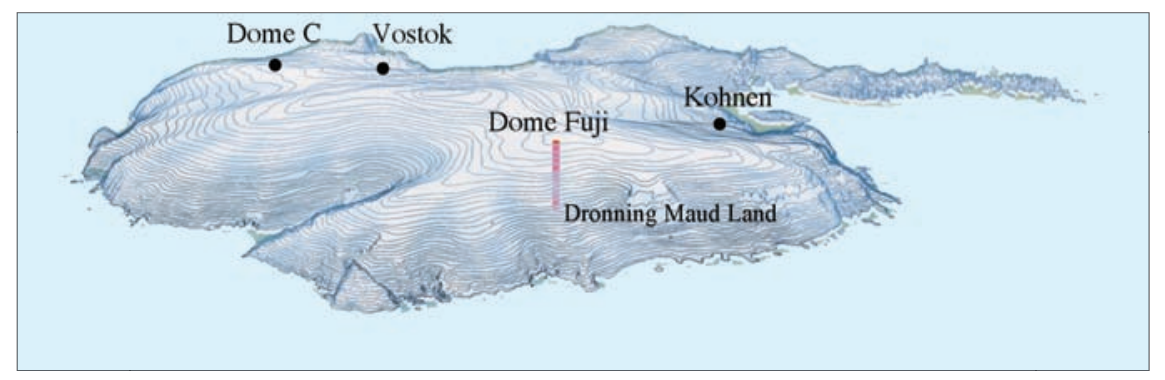

Fig. 1: A bird's eye view of the Antarctic ice sheet. Dome Fuji is located at the summit of Dronning Maud Land. This is the ideal place for ice core climate research because no horizontal ice flow movements occur.

2001/2002 season, and in December 2003, drilling was resumed 40 $\mathrm{m}$ away from the first borehole. This time, we utilized a newly developed, highly efficient drill, using a pipe with small holes $2 \mathrm{~mm}$ in diameter at intervals of $7 \mathrm{~mm}$ to act as a chip chamber to store icecutting chips. We also developed a bulb which prevents ice-cutting

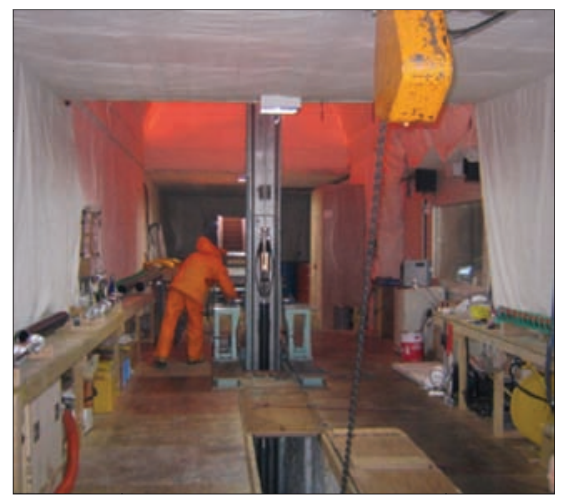

Fig. 2: Deep ice core drilling at Dome Fuji using a newly developed drill with highly efficient performance. chips from flowing out into the borehole when the drill is being winched up. The average drilling depth was $3.7 \mathrm{~m} / \mathrm{run}$ and the speed was $178 \mathrm{~m} /$ week until it got down to $3000 \mathrm{~m}$ depth. This is the fastest performance ever in deep ice core drilling in the Antarctica and Greenland. Figure 2 shows a scene of the deep ice core drilling at Dome Fuji.

Around $3000 \mathrm{~m}$ depth, the drilling speed decreased sharply as the drill hit "warm ice". We took measures against this warm ice, referring to the reports of deep ice coring at Dome C, NGRIP and others. We changed the shape of the drill cutter and the shape of the mount so that they would not easily get frozen and also coated the cutter with Teflon. However, freezing of "water" still made drilling difficult and we could drill only about $0.5 \mathrm{~m}$ each run. 